\title{
Disposable electrochemical immunosensor for analysis of cystatin C, a CKD biomarker
}

\author{
Paula Lopes ， Estefanía Costa-Rama , Idalina Beirão , Henri P.A. Nouws , Alice Santos-Silva , \\ Cristina Delerue-Matos
}

\begin{abstract}
A B S T R A C T
Specific monitoring of cystatin C (CysC) levels in biological fluids is critical for diagnosis, treatment and mechanistic understanding of a spectrum of diseases, particularly chronic kidney disease (CKD). Despite evidences that CysC correlates with the high risk and/or progression of CKD, its use in clinical practice is still scarce. In this context, we report the development of a simple and sensitive immunosensor for the detection of CysC. The biosensor combines the technology of cost-effective screen-printed electrodes with the high specificity of a sandwich immunoassay. Optimized conditions showed that the sensor operates in a linear range between 10 and $100 \mathrm{ng} \mathrm{mL}^{-1}$, with a detection limit and a sensitivity of $6.0 \mathrm{ng} \mathrm{mL}^{-1}$ and $6.4 \pm 0.3 \mu \mathrm{Ang} \mathrm{mL} \mathrm{m}^{-1} \mathrm{~cm}^{-2}$, respectively. Moreover, the sensor provided precise results (RSD $\leq 6.2 \%$ ) and the quantification of CysC in CKD serum samples revealed to be in agreement with the values obtained by a particle-enhanced nephelometric immunoassay. In this light, the proposed immunosensor qualifies for clinical application, constituting a step forward in the development of fast, sensitive and cost-effective diagnostic tools that can improve the current medical care settings of CKD patients.
\end{abstract}

Keywords:

Electrochemical immunosensor

Biomarker

Cystatin C

Chronic kidney disease

Screen-printed electrodes

Gold nanoparticles

\section{Introduction}

Chronic Kidney Disease (CKD) is an enormous public health problem worldwide [1,2]. According to the Global Burden of Disease Study (GBD), in 2015, kidney disease was the 12th most common cause of death around the world with 1.1 million deaths (an increase of $32 \%$ since 2005) $[2,3]$. Due to the increasing prevalence of conditions like diabetes type 2 and hypertension [4-7] among the global population, there has been an increase in the number of individuals affected by CKD. One of the major concerns of CKD is the high prevalence of associated comorbidities and mortality. Most patients are often diagnosed at advanced stages of CKD and may worsen due to complications resulting from late medical intervention [8]. Moreover, CKD is also associated with a huge economic burden: in 2010, 2.62 million people received dialysis worldwide and this fact is estimated to be double by $2030[1,9,10]$. Therefore, early diagnosis and timely intervention are important to prevent disease progression.

There are several renal biomarkers that can be classified as "traditional" and "novel", although a number of the "novel" biomarkers have been used for more than a decade [11]. Glomerular filtration rate (GFR), a "traditional" one, remains as the most widely evaluated parameter of kidney function. It is commonly used to quantify the rate of progression in the vast majority of renal disorders as it estimates the renal clearance in the glomeruli of a particular substance in a unit of time $[\mathrm{mL} / \mathrm{min}][11,12]$. However, since its measurement is time consuming and complex to perform in clinical practice, estimated GFR (eGFR) equations are usually applied to monitor renal function decline. Due to the ease of estimation, GFR readouts are normally based on serum creatinine levels, which may not necessarily reflect a normal GFR interval for a patient, since approximately $10-40 \%$ of urinary creatinine is derived from tubular secretion and increases with the decline of glomerular filtration [13]. There is, therefore, a weak relationship between renal function and serum creatinine at the early stages of CKD until the secretory tubular process is saturated [14].

Among the several "novel" biomarkers (such as neutrophil gelatinase-associated lipocalin (NGAL) or kidney injury molecule-1 (KIM-1)), 
CysC arises as a stronger marker than creatinine for detecting early nephropathy [11,15]: unlike serum creatinine, CysC levels don't dependent on age, gender or muscle weight of the individual [16-18], so it's more reliable in the estimation of renal function. CysC is a $13-\mathrm{kDa}$ cysteine protease inhibitor produced by almost all nucleated cells present in the body at a constant rate. Because of its low-molecular-weight, CysC is freely filtered through the glomerular membrane and nearly completely metabolized by the proximal tubular cells $[19,20]$. All these properties render $\mathrm{CysC}$ as a better estimate of GFR, particularly to detect minor GFR reductions, because the variation of creatinine rises only when kidney function is already significantly impaired $[17,21,22]$. Epidemiologic studies have shown abnormal CysC levels ( $>1 \mathrm{mg} / \mathrm{L}$ ) in people with GFR $<60 \mathrm{~mL} / \mathrm{min} / 1.73 \mathrm{~m}^{2}$, that can be used to classify preclinical kidney disease $[23,24]$. Even though there are many evidences that CysC can contribute to the improvement of the diagnosis of CKD, with potential social and economic significance, its application to clinical diagnosis remains scarce [25].

Several methods have been proposed for the determination of CysC, with the most popular being particle-enhanced turbidimetric and nephelometric immunoassays (PETIA and PENIA, respectively $[17,22,26])$ and enzyme-linked immunosorbent assays (ELISA) [17,27]. Despite sensitive and rapid assays, the automated PETIA and PENIA suffer from costly processes and specific immunoassay instrumentation, which limit their usefulness in daily clinical routine. On the other hand, requirements for relatively expensive test kits and bulky plate readers limit ELISA's usefulness for point of care (POC) diagnostics. In addition to these methods based on immunology, several commercial automated or semi-automated analysers have also emerged in the market offering multiplexed protein biomarker detection. Nevertheless, this type of commercial equipment requires specialized personal and expensive consumables, which again limits their use in health care units where resources can be limited. Photoelectrochemical [28], fluorescence [29], near-infrared spectrometry [30], and LC-MS-based proteomics [31] have recently been reported as alternatives for the detection of CysC, but all of them are currently too expensive and technically complex. As an alternative to the above mentioned methods, electrochemical immunosensors, based on specific antigen-antibody interactions combined with cost-effective, robust and miniaturized transducers, like screenprinted electrodes (SPEs) [32-34], have become the most promising approach to the labour intensive and time consuming assays that are currently used for biomarker analysis [35-37]. Inherent advantages of electrochemical sensors include simple sample pre-treatment procedures, precise results, inexpensive instrumentation, low limits of detection and short time-to-results for the analysis of proteins [38-40]. Moreover, the steps of the immunoassay can be carried out by using small sample volumes $(10-40 \mu \mathrm{L})$ directly on the transducer's surface, which significantly lowers the consumption of expensive reagents, comparatively to other classical methods. SPE-based biosensors are in this way tuned with the growing need for performing rapid, inexpensive and accurate in-situ analysis and for the development of point of care portable devices [34].

The diagnostic significance of serum CysC in "modern diseases" is beyond disputable and underlines the need for complementary laboratory tests in diagnosis, prognosis and availability of treatments that can prevent health complications and significantly improve quality of life. Nevertheless, to the best of our knowledge, an electrochemical immunosensor devoted to the determination of CysC, comprising a simple design, allowing possible integration in POC devices has not yet been reported. In this work, we describe the development of a disposable amperometric immunosensor that can detect CysC through a sandwich-type assay. The design of a highly sensitive immunosensor was achieved using a layer-by-layer construction approach employing gold nanoparticles to generate an amplified response that can be easily detected and measured. This immunosensor allows the determination of CysC in human serum samples, obtaining results that are comparable to those obtained by PENIA. The developed biosensor constitutes a promising tool that can improve and complement the current clinical exams for CKD, allowing an earlier intervention so that the treatment might start when it is most effective.

\section{Materials and methods}

\subsection{Reagents}

The immunoreagents for CysC analysis were purchased from $\mathrm{R} \& \mathrm{D}$ systems: anti-human-CysC mouse monoclonal antibody (anti-CysC; capture antibody for $\mathrm{CysC}, \mathrm{Ab}_{1}$ ), recombinant human $\mathrm{Cys} C$ protein (from mouse myeloma cell line) and anti-human-CysC mouse monoclonal biotinylated antibody (anti-CysC-bio; detection antibody for CysC, $\mathrm{Ab}_{2}$ ). Analytical grade hydrochloric acid, magnesium nitrate hexahydrate, nitric acid ( $\geq 35 \%$ ), sodium chloride, tris(hydroxymethyl) aminomethane, 3 -indoxyl phosphate, $\beta$-casein from bovine milk and streptavidin-alkaline phosphatase (S-AP) from Streptomyces avidinii were all obtained from Sigma-Aldrich. Silver nitrate $(\geq 99,9 \%)$ and tetrachloroauric (III) acid $\left(\mathrm{H}\left[\mathrm{AuCl}_{4}\right]\right)$ were supplied by Alfa Aesar and Merck, respectively.

\subsection{Instrumentation and procedure}

Linear sweep voltammetry (LSV) and the electrodeposition of gold nanoparticles were performed using a potentiostat/galvanostat (PGSTAT101, Metrohm Autolab), controlled by NOVA 1.10 software. Carbon SPEs (SPCE) were obtained from DropSens (Spain) and presented a working electrode, with a diameter of $4.0 \mathrm{~mm}$, made of carbon ink. The counter electrode was also made of carbon ink, whereas the pseudoreference electrode was made of silver. All measurements were performed, at least, in triplicate. Experiments were performed at $22 \pm 1{ }^{\circ} \mathrm{C}$. Scanning electron microscope (SEM) images were obtained at the "Centro de Materias da Universidade do Porto" (CEMUP) using a FEI QUANTA 400 FEG/EDAX Pegasus X4M equipment.

The immunoreagents for CysC were reconstituted following $R \& D$ systems protocols, divided in aliquots and stored at $-80^{\circ} \mathrm{C}$ until used. All immunoassay experiments were conducted using $0.1 \mathrm{M}$ Tris- $\mathrm{HNO}_{3}$ (pH 7.2), designated as buffer 1, except the $3-\mathrm{IP} / \mathrm{Ag}^{+}$(1.0 mM 3-IP and $0.4 \mathrm{mM} \mathrm{AgNO}_{3}$ ) solution which was prepared daily in a $0.1 \mathrm{M}$ Tris$\mathrm{HNO}_{3}$ ( $\mathrm{pH}$ 9.8) containing $20 \mathrm{mM} \mathrm{MgNO}_{3}$, referred throughout the text as buffer 2. All solutions were prepared with deionized water (resistivity = 18.2 M $\Omega \mathrm{cm}$, Millipore Simplicity 185).

\subsection{SPCEs surface nanostructuration}

Electrochemical generation of AuNPs has demonstrated to be a fast method to obtain gold nanostructures in a reproducible way [41]. Briefly, the gold nanostructuration was performed by applying a constant current of $-100 \mu \mathrm{A}$ for $240 \mathrm{~s}$, followed by a constant potential $(0.1 \mathrm{~V})$ for $120 \mathrm{~s}$, using $40 \mu \mathrm{L}$ of a $0.1-\mathrm{mM}\left[\mathrm{AuCl}_{4}\right]^{-}$solution (in $0.1 \mathrm{M}$ $\mathrm{HCl}$ ) [41]. The resulting SPCE-AuNPs were rinsed and left to dry prior to functionalization with $\mathrm{Ab}_{1}$. The morphology of the SPCE-AuNPs was examined by SEM (ESI.1) and the particle size was estimated using Image $J$ software, as reported previously [42]. The AuNPs showed to be uniformly distributed with an average diameter of $33.1 \pm 15.4 \mathrm{~nm}$.

\subsection{Immunoassay procedure for $\mathrm{Cys} C$ detection}

After gold nanostructuration, the working electrode of the SPCEs was functionalised as follows. Step 1: coating with capture antibody $\left(\mathrm{Ab}_{1}, 4 \mu \mathrm{g} \mathrm{mL}, 10 \mu \mathrm{L}\right)$ followed by overnight incubation at $4{ }^{\circ} \mathrm{C}$. The excess and weakly adsorbed antibodies were removed by washing and the free sites were blocked with casein ( $2 \% \mathrm{w} / \mathrm{v}, 40 \mu \mathrm{L}, 30 \mathrm{~min})$. Step 2 : CysC standard solutions ( $40 \mu \mathrm{L}$ of different concentrations) were incubated for $60 \mathrm{~min}$. Step 3: incubation of a biotinylated anti-CysC detection antibody solution $\left(\mathrm{Ab}_{2}, 1 \mu \mathrm{g} \mathrm{mL}{ }^{-1}, 40 \mu \mathrm{L}\right)$ for $60 \mathrm{~min}$. Step 4: the 
tracer enzyme, AP, conjugated with streptavidin (S-AP), was added $(0.2 \mathrm{nM}, 40 \mu \mathrm{L})$ and left to incubate for $60 \mathrm{~min}$. Step 5: the catalysis was carried out by adding a $40-\mu \mathrm{L}$ mixture of 3-IP $(1 \mathrm{mM})$ and silver nitrate $(0.4 \mathrm{mM})$, which was left to react for $20 \mathrm{~min}$ in the dark. After this step, voltammograms were recorded using LSV. The SPCEs were washed after each step with buffer 1 , except after step 4 where buffer 2 was used.

\subsection{Serum samples}

Blood samples were collected from two CKD patients from the Nephrology Service of the Hospital Centre of Porto. The Committee on Ethics, from the Hospital Centre of Porto, approved the study protocol. Patients participated in the study after informed and written consent, respecting their privacy rights. Blood was collected by venepuncture into tubes without anticoagulant, to obtain serum. Samples were processed within $2 \mathrm{~h}$ of collection; aliquots of serum were prepared and immediately stored at $-80{ }^{\circ} \mathrm{C}$ until assayed.

The standard addition method was applied to determine CysC in these samples. Prior to analysis, the samples were diluted (1:50) in buffer 1 to achieve CysC levels within the linear range of the developed immunosensor.

\section{Results and discussion}

\subsection{Immunoassay optimization}

A heterogeneous non-competitive immunoassay (sandwich-type format) was adopted to develop a specific and sensitive immunosensor for CysC detection. The used couple of matched monoclonal antibodies were very selective for CysC (reducing nonspecific binding and crossreactions), thus determinant in the affinity of the antibody-antigen binding. On the basis of the immunoassay format, the AuNPs-modified SPCE was functionalised with capture antibody and the surface blocked to minimise nonspecific adsorption. The sandwich immunocomplex was formed after adding the protein and the biotinylated anti-CysC detection antibody. To trace the immunocomplex formation, the biotinylated anti-CysC antibody was labelled with S-AP, which binds to it through the strong non-covalent interaction biotin-streptavidin. The electrochemical signal was based on the re-oxidation of the enzymatically generated metallic silver, $\mathrm{Ag}^{0}$ : AP hydrolyses 3-IP resulting in an indoxyl intermediate that oxidises to indigo blue and reduces $\mathrm{Ag}^{+}$present in solution to $\mathrm{Ag}^{0}$ which is deposited on the electrode surface $[43,44]$. The AP-catalysed silver deposition reaction was detected through an anodic voltammetric scan (from $0.0 \mathrm{~V}$ to $+0.4 \mathrm{~V}$ at $50 \mathrm{mV} / \mathrm{s}$ ), where the silver peak appears. The obtained peak current intensity is directly proportional to the concentration of the antigen in the sample [43]. A schematic representation of the sensor design and its working principle can be seen in Fig. 1 .

Several experimental variables that affect the immunosensor's performance, such as the amount of (i) capture antibody, (ii) detection antibody, (iii) enzymatic label and (iv) the incubation times were optimized.

\subsubsection{Effect of AuNPs on the analytical signal}

AuNPs are widely recognised to provide a suitable microenvironment for biomolecule immobilization without distorting their bioactivity [45]. They improve the electrochemical signal through a high surface-to-volume ratio, contributing to an effective increase of the amount of antibody immobilized on the surface, and thus enhancing the sensor performance $[41,46]$. As expected, the nanostructured SPCE enhanced the current intensity when compared to the unmodified SPCE (ESI.2) Although for the blank the peak current also increased, the signal-to-blank ratio when the SPCE-AuNP was employed is much higher than for the bare SPCE, clearly improving the sensitivity of the immunosensor. A shift of $100 \pm 6 \mathrm{mV}$ in the oxidation peak potential,

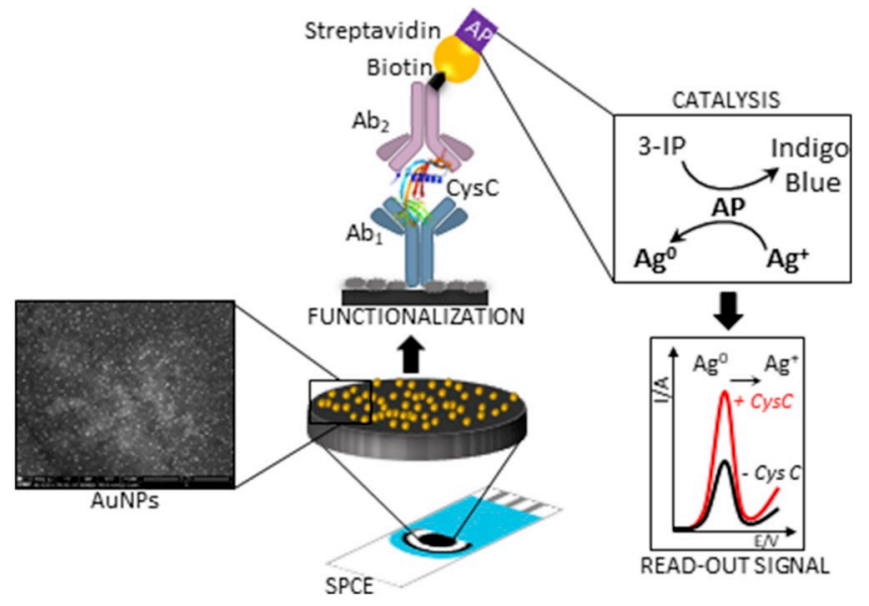

Fig. 1. Schematic representation of the CysC immunosensor design and working principle.

towards less positive potentials, was also observed, showing that the electron transfer is facilitated.

\subsubsection{Optimization of capture and detection antibodies' concentration}

Three different concentrations of capture and detection antibodies, in a total of 9 combinations, were tested as follows: capture antibody solutions (concentrations tested: 2,4 and $6 \mu \mathrm{gL}^{-1}$ ) were placed on the SPCE-AuNPs and incubated overnight at $4^{\circ} \mathrm{C}$. Then, free surface sites were blocked with casein and blank $\left(0 \mathrm{ng} \mathrm{mL} \mathrm{m}^{-1}\right)$ and CysC ( $50 \mathrm{ng} \mathrm{mL}^{-1}$ ) solutions were incubated for $60 \mathrm{~min}$. Detection antibody solutions (concentrations tested: $0.5,1$ and $2 \mu \mathrm{g} \mathrm{mL}^{-1}$ ) were cast on the electrodes and left for $60 \mathrm{~min}$. An S-AP solution was placed on the sensor and left to react for $60 \mathrm{~min}$. Finally, the sensor was washed with buffer 2 and $40 \mu \mathrm{L}$ of the substrate solution, a mixture of 3-IP/ $/ \mathrm{Ag}^{+}(1.0$ $\mathrm{mM} / 0.4 \mathrm{mM}$ ), was left to react during $20 \mathrm{~min}$. Voltammetric measurements were subsequently performed, as indicated in Section 2.4. The results of these optimisations are presented in Fig. 2A. The results of assays 1, 2 and 3 were obtained using combinations of three different concentrations of capture $\left(2,4\right.$ and $\left.6 \mu \mathrm{g} \mathrm{m}^{-1}\right)$ and detection $(0.5,1$ and $2 \mu \mathrm{g} \mathrm{mL}^{-1}$ ) antibodies in a total of 9 different combinations. The peak current intensities increased in the presence of the CysC ( $\left.50 \mathrm{ng} \mathrm{mL} \mathrm{m}^{-1}\right)$, compared to the blank signal $\left(0 \mathrm{ng} \mathrm{mL}{ }^{-1}\right)$, proving that the immunocomplex is formed. The peak current intensity $\left(i_{\mathrm{p}}\right)$ increased with the concentration of $\mathrm{Ab}_{1}$ up to $4 \mu \mathrm{g} \mathrm{mL}^{-1}$ (assays 1 and 2), whereas $6 \mu \mathrm{g} \mathrm{mL}^{-1}$ (assay 3), the highest concentration of $\mathrm{Ab}_{1}$ tested, revealed to be in excess, resulting in a poorer differentiation between the blank and the CysC signal. Assay $2\left(\mathrm{Ab}_{1} 4 \mu \mathrm{g} \mathrm{mL}\right.$ and $\mathrm{Ab}_{2} 0.5,1$ and $2 \mu \mathrm{g} \mathrm{mL}^{-1}$ ) yielded the best sensor performance showing the highest signal-to-blank ratio. Among the three different concentrations (0.5, 1 and $2 \mu \mathrm{g} \mathrm{mL}^{-1}$ ) tested for $\mathrm{Ab}_{2}, 1 \mu \mathrm{g} \mathrm{mL} \mathrm{m}^{-1}$ was the chosen concentration for further studies since the blank signal had the lowest current intensity and a better precision was obtained.

\subsubsection{Optimization of $S-A P$ concentration}

The optimum amount of the enzymatic label was studied using two different concentrations: 0.2 and $0.5 \mathrm{nM}$. The peak current for CysC increased upon raising the S-AP concentration but an appreciable increase in the background current (blank signal) was also observed, which is probably due to the nonspecific adsorption of S-AP on the electrode surface (Fig. 2B). A small amount of BSA (0.1\%) was added to the S-AP solution in separated tests to try to retain the CysC signal while reducing the blank signal. It was observed that the addition of BSA (assay 2') was not effective in comparison with absence of BSA (assay $1^{\prime}$ ), as the current intensity for both the blank and CysC decreased similarly, thus not improving the biosensor's performance (Fig. 2B). In agreement with previous studies $[47,48]$, an S-AP concentration of 

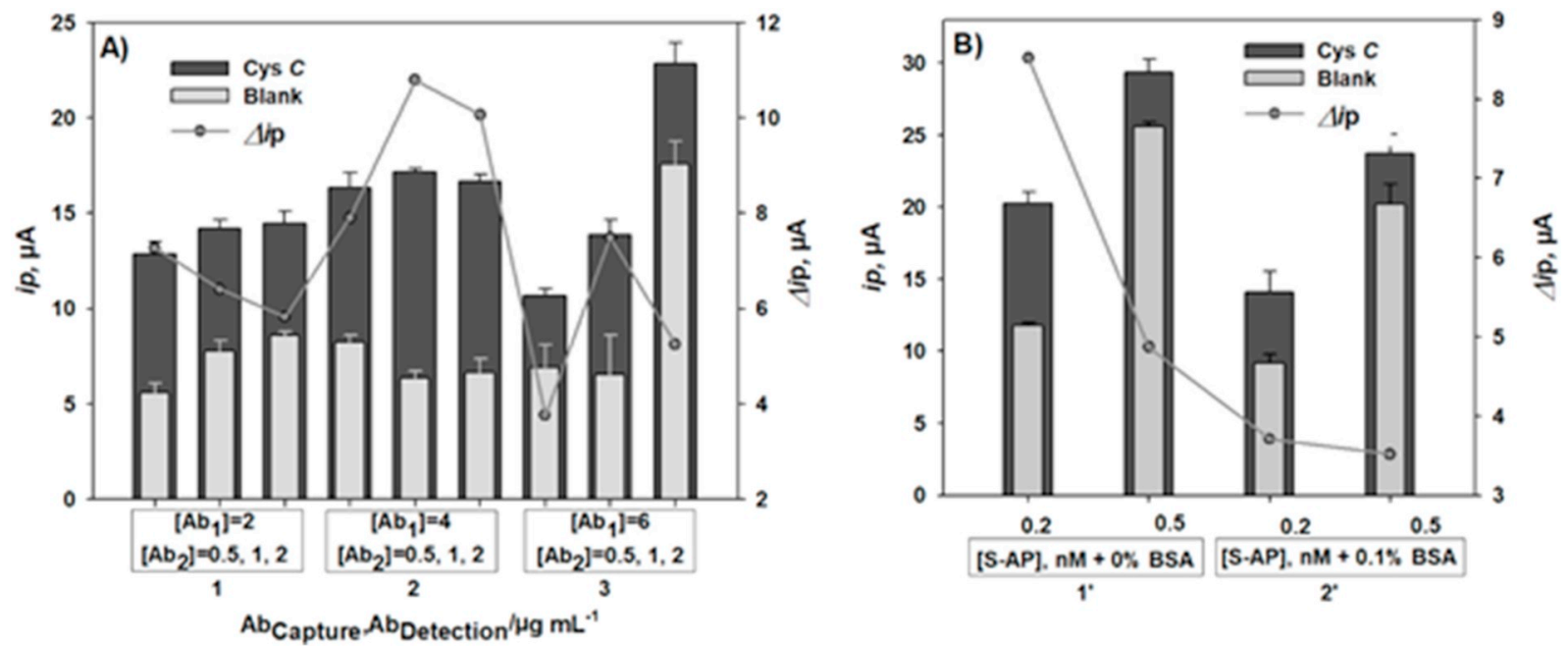

Fig. 2. Peak current intensities obtained by LSV for blank $\left(0 \mathrm{ng} \mathrm{mL}^{-1}\right)$ and CysC $\left(50 \mathrm{ng} \mathrm{mL} \mathrm{m}^{-1}\right)$, and the difference between them $\left(\Delta i_{\mathrm{p}}\right)$; A) different concentrations of capture $\left(\mathrm{Ab}_{1}: 2,4\right.$ and $\left.6 \mu \mathrm{g} \mathrm{mL}^{-1}\right)$ and detection $\left(\mathrm{Ab}_{2}: 0.5,1\right.$ and $\left.2 \mu \mathrm{g} \mathrm{mL}^{-1}\right)$ antibodies; B) different S-AP (0.2 and $\left.0.5 \mathrm{nM}\right)$ concentrations, in the absence and presence of $0.1 \%$ BSA. Other assay conditions: $[\mathrm{S}-\mathrm{AP}]=0.2 \mathrm{nM}$, [Casein $]=2 \%(\mathrm{w} / \mathrm{v}),[3-\mathrm{IP}]=1 \mathrm{mM},\left[\mathrm{AgNO}_{3}\right]=0.4 \mathrm{mM}$. Results are presented as average $\pm \mathrm{SD}$ $(n=3)$.

$0.2 \mathrm{nM}$ was then chosen as optimum and used for further studies.

\subsubsection{Optimization of incubation time(s)}

The sensor's construction and the analysis time was investigated using different assay formats. This was done by combining different assay steps and by pre-incubating the reagents during $30 \mathrm{~min}$ before placement on the sensor surface. The sensor's performance was evaluated using four different assays (Formats: W, X, Y and Z). The results are presented in terms of current variation, $\Delta i_{\mathrm{p}}=i_{\mathrm{c}}-i_{0}$, (where $i_{\mathrm{c}}$ is the observed current at the set concentration of CysC and $i_{0}$ is the blank current), for an easier evaluation of the sensor performance (Fig. 3). Format $W$ : all the steps of the assay were performed sequentially and separately as described in section 2.4; Format $X$ : steps 2 and 3 were combined (i.e. previous mixing of $\mathrm{CysC}$ and $\mathrm{Ab}_{2}$ ); Format $Y$ : steps 3 and 4 were combined (i.e. previous mixing of $\mathrm{Ab}_{2}$ and S-AP); Format $Z$ : combination of steps 3,4 and 5 (i.e. previous mixing of $\mathrm{CysC}, \mathrm{Ab}_{2}$ and S-AP).

As can be observed in Fig. 3, Format X, in which CysC and the anti-

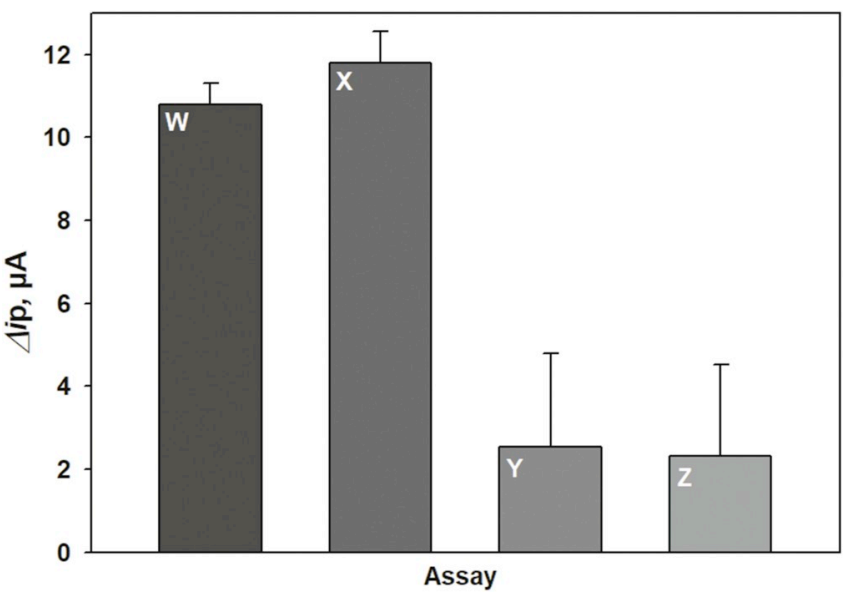

Fig. 3. Performance of the CysC sensor using different assay formats. Current intensities, evaluated by LSV, represented as $\Delta i_{\mathrm{p}}=\mathrm{i}_{\mathrm{c}}-\mathrm{i}_{0}$. Experimental conditions for all assays: $\mathrm{Ab}_{1}\left(4 \mu \mathrm{g} \mathrm{mL} \mathrm{m}^{-1}\right)$; casein $(2 \%)$; $\mathrm{Ab}_{2}\left(1 \mu \mathrm{g} \mathrm{mL} \mathrm{m}^{-1}\right)$; S-AP (0.2 nM); 3-IP ( $1 \mathrm{mM})$ and silver nitrate $(0.4 \mathrm{mM})$. Differences between assays: (W) Addition of all immunoreagents in separated steps; (X) CysC and $\mathrm{Ab}_{2}$ previously mixed; (Y) $\mathrm{Ab}_{2}$ and S-AP previously mixed; and ( $\mathrm{Z}$ ) $\mathrm{CysC}, \mathrm{Ab}_{2}$ and $\mathrm{S}$ AP previously mixed. Results are presented as average $\pm \operatorname{SD}(n=3)$.
CysC detection antibody were pre-incubated, provided the highest $\Delta i_{\mathrm{p}}$. A significant loss of current intensity is evident in Formats $\mathrm{Y}$ and $\mathrm{Z}$. This reduction in current intensity can be attributed to steric effects on the affinity reactions characterised by a steric hindrance factor [49]. On the other hand, the combination of steps 2 and 3 by pre-incubating CysC and detection antibody, Format X, resulted in the optimal sensor performance. This type of format favoured the immunocomplex formation, which may be due to the antigen free binding sites being able to bind to the captured antibody with minimal steric effects. As a result, Format X was selected for further studies since it improves the sensor's design and performance reducing the analysis time in $60 \mathrm{~min}$. In Table 1 a summary of the studied and selected variables is given.

\subsection{Evaluation of the analytical performance of CysC immunosensor}

In order to evaluate the analytical characteristics of the developed immunosensor increasing concentrations of $\mathrm{CysC}$ were measured, under the optimized experimental conditions (summarized in Table 1) and assay Format X. The immunosensor was tested for CysC concentrations up to $750 \mathrm{ng} \mathrm{mL}^{-1}$ (Fig. 4B). The peak current intensity showed a linear relationship with the CysC concentration from 10 to $100 \mathrm{ng} \mathrm{mL}^{-1}$ (Fig. 4) with a determination coefficient of 0.994 according to the following equation: $i_{\mathrm{p}}(\mu \mathrm{A})=(0.803 \pm 0.03) \times[$ CysC $] \quad(\mathrm{ng}$ $\left.\mathrm{mL}^{-1}\right)+(15.09 \pm 1.7)$. It is important to mention that all the metallic silver was oxidised in the first scan because no signal was observed in consecutive scans.

A detection limit of $6.0 \mathrm{ng} \mathrm{mL}^{-1}$ was obtained, calculated from the concentration corresponding to the blank signal plus three times the standard deviation. The sensitivity was found to be $6.4 \pm 0.3 \mu \mathrm{Ang} \mathrm{mL}{ }^{-1} \mathrm{~cm}^{-2}$, which was obtained from the slope of the calibration curve divided by the geometrical area of the working

Table 1

Optimization of the experimental variables of $\mathrm{CysC}$ immunosensor.

\begin{tabular}{lll}
\hline Variable & Range tested & Selected Value \\
\hline $\begin{array}{l}\text { Anti-CysC capture antibody concentration, } \\
\mu \mathrm{g} \mathrm{mL}^{-1}\end{array}$ & $2-6$ & 4 \\
$\begin{array}{l}\text { Anti-CysC detection antibody concentration, } \\
\mu \mathrm{g} \mathrm{mL}^{-1}\end{array}$ & $0.5-2$ & 1 \\
$\begin{array}{l}\text { S-AP concentration, nM } \\
\text { BSA concentration in S-AP solution, \% (w/v) }\end{array}$ & $2-5$ & 2 \\
& $0-0.1$ & 0 \\
\hline
\end{tabular}



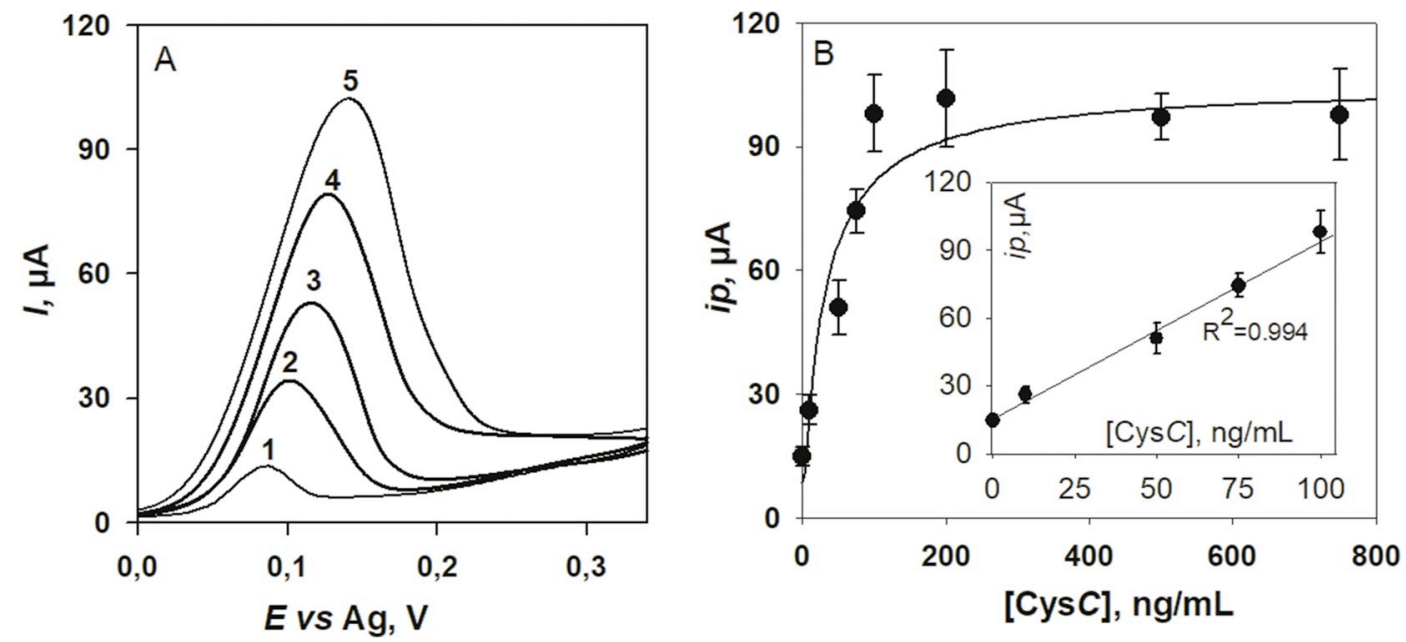

Fig. 4. A) LSV voltammograms obtained with the immunosensor using different CysC concentrations: (1) 0, (2) 10, (3) 50, (4) 75 , and (5) $100 \mathrm{ng} \mathrm{mL}^{-1}$. B) Calibration curve of peak current intensity versus CysC concentration from $0 \mathrm{ng} \mathrm{mL}^{-1}$ to $750 \mathrm{ng} \mathrm{mL}^{-1}$. Inset: linear plot of the peak current intensity versus CysC concentration. Results are presented as average $\pm \operatorname{SD}(n=6)$.

Table 2

Comparison of the results obtained with the proposed electrochemical immunosensor $(\mathrm{n}=3)$ and with PENIA for the determination of CysC in human serum samples.

\begin{tabular}{lll}
\hline & CysC $\left.(\mathrm{ng} \mathrm{mL})^{-1}\right)$ & \\
\cline { 2 - 3 } & Sample A & Sample B \\
\hline PENIA Siemens & 950 & 1650 \\
CysC immunosensor & $917.9 \pm 102.4$ & $1519.6 \pm 143.2$ \\
Relative deviation (\%) & 3.4 & 7.9 \\
\hline
\end{tabular}

electrode. The reproducibility of different sensors was evaluated (RSD $<6.2 \%$, for 6 sensors measuring $50 \mathrm{ng} \mathrm{mL}^{-1} \mathrm{CysC}$ ), demonstrating the potential of the immunosensor as a tool for direct applications in the point-of-care context.

\subsection{Real sample analysis}

To evaluate the immunosensor's performance from a clinical application point of view, the concentration of $\mathrm{CysC}$ was determined in CKD serum samples. As the typical CysC concentration in serum is significantly higher than the highest concentration of the calibration range, a dilution of the serum was carried out (1:50) in buffer 1 . For quantification purposes, and because matrix effects were observed, the standard addition method was used, obtaining slopes of $1.7 \pm 0.4$ and $1.53 \pm 0.07 \mu \mathrm{A} \mathrm{mL} \mathrm{ng}{ }^{-1}$ for samples A and B, respectively. The results for the two samples showed to be in good agreement with those obtained by the current gold standard PENIA (Table 2). This shows that the developed immunosensor enables the detection of CysC in real samples of CKD patients at an early stage of the disease $(1<\mathrm{CysC}<$ $2 \mathrm{mg} \mathrm{mL}^{-1}$ ) or mild decrease in the GFR, offering the advantages of being cost-effective, simple and providing competitive sensitivity, which is required for its use in clinical practice.

\section{Conclusion}

In the present work an electrochemical immunosensor, sandwichtype format, based on SPCE modified with AuNPs, has been developed for quantification of CysC. After optimization, the sensor, that requires very low reagents and sample volumes (in the order of $\mu \mathrm{L}$ ), showed good precision and accuracy and a concentration range with clinical utility. Moreover, the performance of the sensor for CysC quantification in real serum samples was demonstrated.
The design of the developed sensor is economical and efficient when compared with other current methods (e.g. PENIA) and furthermore, the use of screen-printed electrodes provides the sensor with a huge potential to be integrated in a PoC device with the aim of improving the current clinical practice. Although the dilution step for sample analysis is a limitation, which can be further improved, the developed biosensor offers many advantages compared to other methods: simplicity, ease of manufacture, rapid response, portability and no need of complex instrumentation or sample pre-treatment.

Therefore, the biosensor here described is a useful tool for simple and decentralized CysC determination, contributing to improve the early diagnosis of CKD and allowing an early treatment and the prevention of the progression of the CKD.

\section{Acknowledgements}

This work was supported by European Union through projects Norte-01-0145-FEDER-000024 and Norte-01-0145-FEDER-000011, cofunded by FEDER in the scope of CCDR-N and NORTE2020 Partnership Agreement. This work also received financial support from the European Union (FEDER funds through COMPETE) and National Funds (FCT, Fundação para a Ciência e a Tecnologia) through project UID/ QUI/50006/2013.

\section{References}

[1] https://www.kidney.org/kidneydisease/global-facts-about-kidney-disease (Last accessed February 2019).

[2] G. 2015 M., C. of D. Collaborators, Global, regional, and national life expectancy, all-cause mortality, and cause-specific mortality for 249 causes of death, 1980-2015: a systematic analysis for the Global Burden of Disease Study 2015, Lancet 388 (2016) 1459-1544, https://doi.org/10.1016/S0140-6736(16)31012-1.

[3] B.L. Neuen, S.J. Chadban, A.R. Demaio, D.W. Johnson, V. Perkovic, Chronic kidney disease and the global NCDs agenda, BMJ Glob. Health 2 (2017) e000380, , https:// doi.org/10.1136/bmjgh-2017-000380.

[4] C. Angelidis, S. Deftereos, G. Giannopoulos, N. Anatoliotakis, G. Bouras, G. Hatzis, V. Panagopoulou, V. Pyrgakis, M.W. Cleman, Cystatin C: an emerging biomarker in cardiovascular disease, Curr. Top. Med. Chem. 13 (2013) 164-179, https://doi.org/ $10.2174 / 1568026611313020006$.

[5] Temesgen Fiseha, Cystatin C - a biomarker for early nephropathy in Type 2 diabetic patients, J. Mol. Biomark. Diagn. (2015), https://doi.org/10.4172/2155-9929.S8009. 
[6] https://www.worldkidneyday.org/faqs/topics/acute-kidney-injury/ (Last accessed February 2019).

[7] V. Jha, G. Garcia-garcia, K. Iseki, Z. Li, S. Naicker, B. Plattner, R. Saran, A.Y. Wang, C. Yang, Global Kidney Disease 3 Chronic kidney disease : global dimension and perspectives, Lancet 382 (2013) 260-272, https://doi.org/10.1016/S01406736(13)60687-X

[8] M. Tonelli, N. Wiebe, B. Culleton, A. House, C. Rabbat, M. Fok, F. McAlister, A.X. Garg, Chronic kidney disease and mortality risk: a systematic review, J. Am. Soc. Nephrol. 17 (2006) 2034-2047, https://doi.org/10.1681/ASN.2005101085.

[9] T. Liyanage, T. Ninomiya, V. Jha, B. Neal, H.M. Patrice, I. Okpechi, M. Zhao, J. Lv, A.X. Garg, J. Knight, A. Rodgers, M. Gallagher, S. Katwal, A. Cass, V. Perkovic, Worldwide access to treatment for end-stage kidney disease: a systematic review, Lancet 385 (2013) 1975-1982, https://doi.org/10.1016/S0140-6736(14)61601-9.

[10] V.A. Luyckx, M. Tonelli, J.W. Stanifer, The global burden of kidney disease and the sustainable development goals, Bull. World Health Organ. 96 (2018) 414-422, https://doi.org/10.2471/BLT.17.206441.

[11] S.M. Ford, Conventional and emerging renal biomarkers, in: R.C. Gupta (Ed.), Biomarkers Toxicol. Elsevier Inc., 2014, pp. 261-268, , https://doi.org/10.1016/ B978-0-12-404630-6.00014-2.

[12] L.A. Stevens, J. Coresh, T. Greene, A.S. Levey, Assessing kidney function - measured and estimated glomerular filtration rate, N. Engl. J. Med. 354 (2006) 2248-2473, https://doi.org/10.1056/NEJMra054415.

[13] O.F. Laterza, C.P. Price, M.G. Scott, Cystatin C: an improved estimator of glomerular filtration rate? Clin. Chem. 48 (2002) 699-707.

[14] M.T. James, B.R. Hemmelgarn, M. Tonelli, Early recognition and prevention of chronic kidney disease, Lancet 375 (2010) 1296-1309, https://doi.org/10.1016/ S0140-6736(09)62004-3.

[15] C.L. Edelstein, Biomarkers in acute kidney injury, in: C.L. Edelstein (Ed.), Biomarkers Kidney Dis, second ed., Elsevier Inc., 2017, pp. 241-315, , https://doi. org/10.1016/B978-0-12-803014-1/00006-6.

[16] S. Lopez-Giacoman, M. Madero, Biomarkers in chronic kidney disease, from kidney function to kidney damage, World J. Nephrol. 4 (2015) 57-73, https://doi.org/10. 5527/wjn.v4.i1.57.

[17] A. Onopiuk, A. Tokarzewicz, E. Gorodkiewicz, Cystatin C: a kidney function biomarker, Adv. Clin. Chem. first ed., Elsevier Inc., 2015, pp. 57-69, , https://doi.org/ 10.1016/bs.acc.2014.11.007.

[18] A. Ogawa-Akiyama, H. Sugiyama, M. Kitagawa, K. Tanaka, A. Onishi, T. Yamanari, H. Morinaga, H.A. Uchida, K. Nakamura, H. Ito, J. Wada, Serum cystatin C is an independent biomarker associated with the renal resistive index in patients with chronic kidney disease, PLoS One 13 (2018) e0193695, , https://doi.org/10.1371/ journal.pone.0193695.

[19] R.G. Fassett, S.K. Venuthurupalli, G.C. Gobe, J.S. Coombes, M.A. Cooper, W.E. Hoy, Biomarkers in chronic kidney disease: a review, Kidney Int. 80 (2011) 806-821, https://doi.org/10.1038/ki.2011.198.

[20] E. Coll, A. Botey, L. Alvarez, E. Poch, L. Quintó, A. Saurina, M. Vera, C. Piera, A. Darnell, Serum cystatin C as a new marker for noninvasive estimation of glomerular filtration rate and as a marker for early renal impairment, Am. J. Kidney Dis. 36 (2000) 29-34, https://doi.org/10.1053/ajkd.2000.8237.

[21] S. Herget-Rosenthal, G. Marggraf, J. Hüsing, F. Göring, F. Pietruck, O. Janssen, T. Philipp, A. Kribben, Early detection of acute renal failure by serum cystatin C, Kidney Int. 66 (2004) 1115-1122, https://doi.org/10.1111/j.1523-1755.2004. 00861.x.

[22] J. Kyhse-Andersen, C. Schmidt, G. Nordin, B. Andersson, P. Nilsson-Ehle, V. Lindström, A. Grubb, Serum cystatin C, determined by a rapid, automated particle-enhanced turbidimetric method, is a better marker than serum creatinine for glomerular filtration rate, Clin. Chem. 40 (1994) 1921-1926.

[23] J.H. Ix, M.G. Shlipak, G.M. Chertow, M.A. Whooley, Association of cystatin C with mortality, cardiovascular events, and incident heart failure among persons with coronary heart disease: data from the heart and soul study, Circulation 115 (2007) 173-179, https://doi.org/10.1161/CIRCULATIONAHA.106.644286.

[24] M. Dupont, Y. Wu, S.L. Hazen, W.H.W. Tang, Cystatin C identifies patients with stable chronic heart failure at increased risk for adverse cardiovascular events, Circ. Heart Fail. 5 (2012) 602-609, https://doi.org/10.1161/CIRCHEARTFAILURE.112. 966960.

[25] M.G. Shlipak, M.D. Mattes, C.A. Peralta, Update on cystatin C: incorporation into clinical practice, Am. J. Kidney Dis. 62 (2013) 595-603, https://doi.org/10.1053/j. ajkd.2013.03.027.

[26] H. Finney, D.J. Newman, W. Gruber, P. Merle, C.P. Price, Initial evaluation of cystatin $\mathrm{C}$ measurement by particle-enhanced immunonephelometry on the Behring nephelometer systems (BNA, BN II), Clin. Chem. 43 (1997) 1016-1022.

[27] J.W.A. Findlay, W.C. Smith, J.W. Lee, G.D. Nordblom, I. Das, B.S. DeSilva, M.N. Khan, R.R. Bowsher, Validation of immunoassays for bioanalysis: a pharmaceutical industry perspective, J. Pharm. Biomed. Anal. 21 (2000) 1249-1273, https://doi.org/10.1016/S0731-7085(99)00244-7.

[28] L. Mi, P. Wang, J. Yan, J. Qian, J. Lu, J. Yu, Y. Wang, H. Liu, M. Zhu, Y. Wan, S. Liu, A novel photoelectrochemical immunosensor by integration of nanobody and TiO 2 nanotubes for sensitive detection of serum cystatin C, Anal. Chim. Acta 902 (2015) 107-114, https://doi.org/10.1016/j.aca.2015.11.007.

[29] H. Lin, L. Li, C. Lei, X. Xu, Z. Nie, M. Guo, Y. Huang, S. Yao, Immune-independent and label-free fluorescent assay for Cystatin C detection based on protein-stabilized Au nanoclusters, Biosens. Bioelectron. 41 (2013) 256-261, https://doi.org/10. 1016/j.bios.2012.08.030.

[30] J. Tao, P. Zhao, Q. Zeng, The determination of cystatin C in serum based on labelfree and near-infrared light emitted PbS@BSA QDs, J. Mater. Chem. B. 4 (2016) 4258-4262, https://doi.org/10.1039/c6tb00080k.

[31] A.M. Hawkridge, D.C. Muddiman, Mass spectrometry-based biomarker discovery: toward a global proteome index of individuality, Annu. Rev. Anal. Chem. 2 (2009) 265-277, https://doi.org/10.1146/annurev.anchem.1.031207.112942.

[32] K.K. Mistry, K. Layek, A. Mahapatra, C. RoyChaudhuri, H. Saha, A review on amperometric-type immunosensors based on screen-printed electrodes, Analyst 139 (2014) 2289-2311, https://doi.org/10.1039/c3an02050a.

[33] R.A.S. Couto, J.L.F.C. Lima, M.B. Quinaz, Recent developments, characteristics and potential applications of screen-printed electrodes in pharmaceutical and biological analysis, Talanta 146 (2016) 801-814, https://doi.org/10.1016/j.talanta.2015.06. 011.

[34] Y. Wan, Y. Su, X. Zhu, G. Liu, C. Fan, Development of electrochemical immunosensors towards point of care diagnostics, Biosens. Bioelectron. 47 (2013) 1-11, https://doi.org/10.1016/j.bios.2013.02.045.

[35] E. Engvall, P. Perlmann, Enzyme-linked immunosorbent assay (ELISA) Quantitative assay of immunoglobulin G, Immunochemistry 8 (1971) 871-874, https://doi.org/ 10.1016/0019-2791(71)90454-X.

[36] L. Cai, J. Borowiec, S. Xu, W. Han, P. Venge, Assays of urine levels of HNL/NGAL in patients undergoing cardiac surgery and the impact of antibody configuration on their clinical performances, Clin. Chim. Acta 403 (2009) 121-125, https://doi.org/ 10.1016/j.cca.2009.01.030.

[37] A. Nagai, Y. Murakawa, M. Terashima, K. Shimode, N. Umegae, H. Takeuchi, S. Kobayashi, Cystatin C and cathepsin B in CSF from patients with inflammatory neurologic diseases, Neurology 55 (2000) 1828-1832, https://doi.org/10.1212/ WNL.55.12.1828

[38] S.C.B. Gopinath, T.H. Tang, M. Citartan, Y. Chen, T. Lakshmipriya, Current aspects in immunosensors, Biosens. Bioelectron. 57 (2014) 292-302, https://doi.org/10. 1016/j.bios.2014.02.029.

[39] T.R.J. Holford, F. Davis, S.P.J. Higson, Recent trends in antibody based sensors, Biosens. Bioelectron. 34 (2012) 12-24, https://doi.org/10.1016/j.bios.2011.10. 023.

[40] F.S. Felix, L. Angnes, Electrochemical immunosensors - a powerful tool for analytical applications, Biosens. Bioelectron. 102 (2018) 470-478, https://doi.org/10. 1016/j.bios.2017.11.029.

[41] G. Martínez-Paredes, M.B. González-García, A. Costa-García, In situ electrochemical generation of gold nanostructured screen-printed carbon electrodes. Application to the detection of lead underpotential deposition, Electrochim. Acta 54 (2009) 4801-4808, https://doi.org/10.1016/j.electacta.2009.03.085.

[42] R.C. Alves, F.B. Pimentel, H.P.A. Nouws, W. Correr, M.B. González-García, M.B.P.P. Oliveira, C. Delerue-Matos, Detection of the peanut allergen Ara h 6 in foodstuffs using a voltammetric biosensing approach, Anal. Bioanal. Chem. 407 (2015) 7157-7163, https://doi.org/10.1007/s00216-015-8879-8.

[43] P. Fanjul-Bolado, D. Hernández-Santos, M.B. González-García, A. Costa-García, Alkaline phosphatase-catalyzed silver deposition for electrochemical detection, Anal. Chem. 79 (2007) 5272-5277, https://doi.org/10.1021/ac070624o.

[44] V. Escamilla-Gómez, D. Hernández-Santos, M.B. González-García, J.M. PingarrónCarrazón, A. Costa-García, Simultaneous detection of free and total prostate specific antigen on a screen-printed electrochemical dual sensor, Biosens. Bioelectron. 24 (2009) 2678-2683, https://doi.org/10.1016/j.bios.2009.01.043.

[45] A.A. Karyakin, G.V. Presnova, M.Y. Rubtsova, A.M. Egorov, Oriented immobilization of antibodies onto the gold surfaces via their native thiol groups, Anal. Chem. 72 (2000) 3805-3811, https://doi.org/10.1021/AC9907890.

[46] J.M. Pingarrón, P. Yáñez-Sedeño, A. González-Cortés, Gold nanoparticle-based electrochemical biosensors, Electrochim. Acta 53 (2008) 5848-5866, https://doi. org/10.1016/j.electacta.2008.03.005.

[47] R.C. Alves, F.B. Pimentel, H.P.A. Nouws, R.C.B. Marques, M.B. González-García, M.B.P.P. Oliveira, C. Delerue-Matos, Detection of Ara h 1 (a major peanut allergen) in food using an electrochemical gold nanoparticle-coated screen-printed immunosensor, Biosens. Bioelectron. 64 (2015) 19-24, https://doi.org/10.1016/j. bios.2014.08.026

[48] R.C.B. Marques, S. Viswanathan, H.P.A. Nouws, C. Delerue-Matos, M.B. González García, Electrochemical immunosensor for the analysis of the breast cancer biomarker HER2 ECD, Talanta 129 (2014) 594-599, https://doi.org/10.1016/j. talanta.2014.06.035.

[49] W.S. Hlavacek, R.G. Posner, A.S. Perelson, Steric effects on multivalent ligand-receptor binding: exclusion of ligand sites by bound cell surface receptors, Biophys. J. 76 (1999) 3031-3043, https://doi.org/10.1016/S0006-3495(99)77456-4. 